\title{
da proteção à instrução: mobilizações prático-discursivas em torno da infância nos debates sobre gênero e sexualidade na educação
}

\author{
amana rocha mattos ${ }^{1}$ \\ universidade do estado do rio de janeiro \\ orcid id: https:/ / orcid.org/0000-0002-2890-5421 \\ rafael cavalheiro ${ }^{2}$ \\ universidade do estado do rio de janeiro \\ orcid id: https:/ / orcid.org/0000-0003-2907-8293
}

\section{resumo}

Este artigo discute como alguns sentidos de infância têm sido acionados nos enfrentamentos sobre a legitimidade das temáticas de gênero e sexualidade na educação, considerando-se o cenário contemporâneo no país. Para isso, analisaremos duas armadilhas prático-discursivas que têm se consolidado. A primeira, forjada pelos atores da ofensiva antigênero, consiste na construção narrativa da infância vulnerável, a ser protegida, e aciona o pânico moral contra as discussões sobre gênero e sexualidade nas escolas. A segunda armadilha, mais sutil, diz do lugar de passividade em que são tomados as e os estudantes no contexto escolar, enquanto objeto da instrução pedagógica - inclusive quando são abordados os temas de gênero e sexualidade em sala de aula. A imagem de uma criançapresa dos "ideólogos de gênero", passiva e em perigo, povoa as falas analisadas na primeira sessão, e permite-nos discutir os usos políticos mitigados pela hiperinflação dessa ideia de vulnerabilidade infantil. Entretanto, mesmo em práticas educativas que apostam no trabalho com questões de gênero e sexualidade nos contextos escolares, observamos que a menoridade pode ser pensada em perspectivas conservadoras e sem agência, como discutido na segunda sessão. Para tensionar essas lógicas, pontuamos a dimensão do lúdico e da brincadeira como ferramentas conceituais e metodológicas que podem contribuir com uma abordagem não pedagogizante da sexualidade e do gênero no campo da educação.

palavras-chave: educação; infância; gênero; sexualidade; heteronormatividade.

\section{from protection to instruction: practical-discursive mobilizations around childhood in debates about gender and sexuality in education}

\section{abstract}

This article discusses how assumptions about the nature of childhood have been triggered in the confrontations about the legitimacy of gender and sexuality themes in education in contemporary Brazil. We analyse two practical-discursive pitfalls that have been consolidated in these confrontations. The first, forged by anti-gender discussion and education activists, consists in the narrative construction of vulnerable childhood to be protected, and triggers moral panic at the prospect of discussions about gender and sexuality in schools. The second, more subtle trap, concerns the situation of passivity attributed to students in the school context, who are considered to be the subjects of instruction by teachers, including those moments when gender and sexuality issues are addressed in the classroom. The image of a child-prisoner, passive and in danger made-up by the "gender ideologues," populates the narratives analysed in the first part of the paper. It allows us to discuss the political uses of the hyperinflation of this idea of child

\footnotetext{
1 E-mail: amanamattos@gmail.com

2 E-mail: rafaelatler@gmail.com
} 
vulnerability. However, even in educational practices that invest in working gender and sexuality matters in school setting, we observe that children can be conceived as lacking agency, such as discussed in the paper's second part. In order to challenge these logics, we highlight the ludic dimension and playing with conceptual and methodological tools that can contribute to a non-pedagogizing approach to gender and sexuality in education.

keywords: education; childhood; gender; sexuality; heteronormativity.

\section{de la protección a la instrucción: movilizaciones prácticas-discursivas en torno a la infancia en los debates sobre género y sexualidad en la educación.}

\section{resumen}

Este artículo analiza cómo algunos sentidos de la infancia se han activado en las confrontaciones sobre la legitimidad de los temas de género y sexualidad en la educación, considerando el escenario contemporáneo de Brasil. Para esto, analizaremos dos trampas práctico-discursivas que se han consolidado. La primera, forjada por los actores de la ofensiva anti-género, consiste en la construcción narrativa de la infancia vulnerable, que necesita ser protegida, y acciona el pánico moral contra las discusiones sobre género y sexualidad en las escuelas. La segunda trampa, más sutil, se refiere al lugar de pasividad en que son colocados los y las estudiantes en el contexto escolar, en cuanto objeto de instrucción pedagógica- incluso cuando son abordados los temas de género y sexualidad en el salón de clases. La imagen de un niño y niña prisionero de los "ideólogos de género", pasivo y en peligro, puebla las declaraciones analizadas en la primera sesión, y nos permite discutir los usos políticos mitigados por la hiperinflación de esta idea de vulnerabilidad infantil. Sin embargo, incluso en las prácticas educativas que se centran en trabajar con cuestiones de género y sexualidad en contextos escolares, observamos que la minoría se puede pensar en perspectivas conservadoras y sin agencia, como se discutió en la segunda sesión. Para tensionar estas lógicas, señalamos la dimensión lúdica y el juego como herramientas conceptuales y metodológicas que pueden contribuir a un enfoque no pedagógico de la sexualidad y el género en el campo de la educación.

palabras clave: educación; infância; género; sexualidade; heteronormatividad. 
da proteção à instrução: mobilizações prático-discursivas em torno da infância nos debates sobre gênero e sexualidade na educação

\section{introdução}

“Salvem as nossas crianças!" - aos gritos, essa frase foi proferida por manifestantes em frente ao prédio onde estava sendo realizada a conferência de Judith Butler por ocasião do evento organizado pelo Sesc Pompeia em novembro de 2017, em São Paulo. A vinda de Butler ao Brasil gerou intensa mobilização nas redes sociais, especialmente entre os setores políticos conservadores e religiosos. Butler, na época, foi alçada à categoria de "mãe da ideologia de gênero" e sua visita ao país foi explicitamente associada por Joice Hasselmann, deputada federal pelo Estado de São Paulo, ao "ataque" e à "corrupção da infância". Curiosamente, o evento que motivou a vinda da filósofa não tratava nem de infância nem de gênero, mas sim dos "Fins da Democracia" 3 . A virulência dos ataques à fala da filósofa não foi aleatória. Apontava para algo que hoje nos parece mais nítido: a infância, enquanto campo e ideia, está em disputa, sobretudo quando articulada às questões de gênero e sexualidade ${ }^{4}$.

Neste artigo propomos pensar como os sentidos de infância têm sido tomados, no atual contexto político brasileiro, nos debates sobre a legitimidade das temáticas de gênero e de sexualidade na educação, considerando-se o avanço da ofensiva antigênero (Correa; Kalil, 2020). Tanto no âmbito político quanto no religioso, e mesmo no campo da educação, as relações entre infância, gênero e sexualidade têm se dado com muitas tensões. Partindo de um referencial teórico que pensa "infância" em suas dimensões históricas e culturais, frequentemente

\footnotetext{
3 "Protesto contra Judith Butler", disponível em $<$ https://www.youtube.com/watch?v=S9p9tYJoYJw>; "As vozes da pequena grande batalha do Sesc Pompeia", disponível em

<https://brasil.elpais.com/brasil/2017/11/07/politica/1510085652_717856.html>; “Filósofa Judith Butler é agredida em aeroporto de SP e mulher leva tapa ao defendê-la", disponível em <https://g1.globo.com/sao-paulo/noticia/filosofa-judith-butler-e-alvo-de-ofensas-em-aeroportode-sp-e-mulher-e-agredida-ao-defende-la.ghtml>

${ }^{4}$ Neste artigo, iremos aproximar os campos dos estudos de gênero e de sexualidade. Reconhecemos, entretanto, que tais campos abarcam uma enorme diversidade de perspectivas teóricas, metodológicas e políticas, que não serão exploradas minuciosamente dados os objetivos deste trabalho.
} 
articuladas à reiteração de normatividades, este trabalho discute atravessamentos específicos que têm se produzido nos debates públicos e educacionais no que se refere a gênero e sexualidade nas escolas. Para tanto, analisaremos duas armadilhas discursivas e práticas que têm se consolidado no cenário atual.

A primeira, mais ostensiva, é a narrativa sobre a infância forjada pelos atores da ofensiva antigênero, que remete as crianças à proteção familiar em uma promoção do pânico moral e de sua vulnerabilidade frente aos debates de gênero e de sexualidade nas escolas e na cultura de maneira geral. A ofensiva é atravessada por diversas questões políticas, e materializa-se nos discursos moralizantes em torno da infância. Analisamos, na primeira sessão, falas de atores da política brasileira atual, em um cenário em que visões salvacionistas da "criança" e da "família" foram mobilizadas em um contexto eleitoral marcado pela polarização política, por pautas ultraconservadoras e pela reiteração do medo enquanto afeto político. Para tanto, lançamos mão de autores/as que pensam o gênero e a sexualidade como campos políticos, bem como o lugar que a infância assume nas pautas conservadoras. Discutimos, ainda, como a noção de progresso, associada à infância, põe em cena a heteronormatividade e o controle dos corpos e experiências infantis.

A imagem de uma criança-presa dos "ideólogos de gênero", passiva e em perigo, povoa as falas analisadas na primeira sessão, e permite-nos discutir os usos políticos mitigados pela hiperinflação da ideia de vulnerabilidade infantil. Entretanto, mesmo em práticas educativas que apostam no trabalho com questões de gênero e sexualidade nos contextos escolares, observamos que a menoridade pode ser pensada em perspectivas conservadoras e sem agência.

Assim, propomos a discussão da segunda armadilha prático-discursiva mais sutil do que a primeira - que se caracteriza pela consolidação do lugar do/a estudante como passivo/a e como sujeito a ser "instruído" na escola, inclusive em relação a tais temáticas. Nesse sentido, discutiremos como o recurso à "transmissão de informação" é feito por docentes que abordam esses temas em sala de aula, demarcando lugares estáveis e hierarquizados na relação de ensino-aprendizagem. Para tensionar essa lógica, trazemos a dimensão do lúdico e da brincadeira como 
ferramentas conceituais e metodológicas que podem contribuir com uma abordagem não pedagogizante da sexualidade e do gênero no campo da educação.

\section{narrativas moralizantes sobre a infância na ofensiva antigênero}

Os ataques a políticas públicas, docentes, pesquisadores/as e instituições que pautam questões de gênero e de sexualidade se consolidaram nos últimos anos em um movimento que vem sendo nomeado de "ofensiva antigênero" (Correa, 2018; Correia; Kalil, 2020; Junqueira, 2018; Prado; Correa, 2018). Esse fenômeno transnacional mobiliza diversos agentes, assumindo contornos distintos em diferentes lugares do globo - apesar de guardarem algumas similaridades. A produção do truque discursivo da "ideologia de gênero" certamente é um deles (Mattos, 2018). Tendo suas bases na igreja católica, o combate à “ideologia de gênero" já se fazia presente nos discursos do Cardeal Joseph Ratzinger ainda na década de 1990. Posteriormente, na condição de Papa Bento XVI, afirmou que um dos eixos de combate da igreja católica deveria ser a "ideologia de gênero", pensamento nefasto que através de uma tentativa de manipular a natureza visaria eliminar o poder criacional de Deus (Junqueira, 2018) 5 .

Genealogicamente, o investimento do Papa vincula-se ao ideal de família preconizado pela igreja - a família heterossexual, ponto nodal a partir do qual se engendra o discurso da "ideologia de gênero". De certo modo, esse discurso é uma continuidade e uma reatualização de um movimento que já estava presente em João Paulo II e que foi tomando maior proporção após a Conferência de Beijing (Correa, 2018). Alguns anos mais tarde, vemos a capilarização dos ataques ao gênero em leituras caricaturais. Uma delas, bastante comum e amplamente utilizada pelos setores ultraconservadores, é a compreensão do gênero como uma ideologia de cunho puramente sociológico, que promoveria uma "confusão generalizada" nas crianças por partir de premissas que negariam a biologia. Os corpos biológicos são tomados nessa leitura de forma naturalizada, e qualquer questionamento em relação à arbitrariedade do sistema sexo-gênero-desejo (Butler, [1990] 2016) seria

\footnotetext{
${ }^{5}$ Naturalmente, essa não é uma leitura hegemônica. O trabalho de Correa (2018) situa a articulação do Vaticano que antecede Ratzinger, mas é a partir de Bento XVI que os ataques ao gênero ganham centralidade.
} 
da proteção à instrução: mobilizações prático-discursivas em torno da infância

causa de "confusão" para as crianças, o que justificaria serem questionamentos nocivos à infância (Corrêa; Kalil, 2020). Essa leitura produz uma imagem estereotipada dos estudos de gênero, com simplificações que promovem o alarmismo entre familiares e educadores/as. Como sintetiza Butler,

parece não haver interesse no que o campo complexo e conflituoso dos estudos de gênero e de sexualidade realmente inclui. Este é resumido em um fantasma que serve para justificar o fato de que quase ninguém lê os textos do campo, ou considera seus argumentos. (Butler, 2019a, p. 3, tradução nossa).

No que se refere à ofensiva antigênero, trabalhos como os de Junqueira (2018), Patternote e Kuhar (2018), Butler (2020) e Correa e Kalil (2020) mostram como os mapas e eixos de ataque da ofensiva vão se articulando em diferentes contextos. Como adverte Sonia Corrêa (2019), não devemos tomar esse fenômeno como algo isolado e demasiadamente particular, sendo necessário considerar a dimensão transnacional da ofensiva. Porém, devido ao escopo deste escrito, iremos nos restringir à situação brasileira.

Um evento central desse contexto político foi o processo eleitoral de 2018, quando a referência à infância e à "ideologia de gênero" mobilizou a sociedade. A campanha do presidente eleito, Jair Bolsonaro, baseou-se em larga escala em fake news sobre o "kit gay" e a "ideologia de gênero" nas escolas. Por ocasião da entrevista realizada em 28 de agosto de 2018 no Jornal Nacional6, Bolsonaro mostrou um livro que representaria o "kit gay" e disse que estava "defendendo as crianças em sala de aula"7. Em seu primeiro discurso como presidente, disse que o combate à "ideologia de gênero" seria um eixo basilar do governo ${ }^{8}$.

Não por acaso, no período pré-eleitoral, dois apoiadores do então candidato Jair Bolsonaro envolveram-se nos protestos contra a vinda da filósofa Judith Butler ao Brasil. Joice Hasselmann, deputada federal mais votada do estado de São Paulo, e Kim Kataguiri, deputado eleito por São Paulo e integrante do Movimento Brasil Livre, fizeram vídeos incitando a criação de abaixo-assinados e formas de

\footnotetext{
${ }^{6}$ Disponível em: <https://globoplay.globo.com/v/6980200/>

${ }^{7}$ Nessa mesma entrevista, Bolsonaro diz que: "um pai não quer chegar em casa e encontrar um filho brincando de boneca por influência da escola".

${ }^{8}$ Disponível em: <https:/ / www.youtube.com/watch?v=3nXOjJ-BP5M>
} 
sabotagem à visita da filósofa ao país 9 . A atual ministra da Família, da Mulher e dos Direitos Humanos, Damares Alves, também integrou o rol de apoiadores do candidato à presidência, fazendo falas inflamadas sobre o assunto. Trazemos, a seguir, algumas falas da ministra e dos deputados mencionados, que articulam as noções de "ideologia de gênero" e infância.

Kataguiri $(2017)^{10}$ refere-se à “ideologia de gênero" como um “câncer" para as crianças. Segundo o deputado, através dessa "ideologia" as crianças teriam a possibilidade de realizar intervenções corporais para mudança de sexo desde a primeira infância. Para o deputado (Kataguiri, 2018)11, os pais é que deveriam falar com os filhos sobre sexualidade, e não a escola. O debate sobre o assunto nas escolas não é entendido por Kataguiri como parte do processo educativo, mas como "militância" e "palanque eleitoral" associado a partidos de esquerda. Hasselmann $(2017)^{12}$, por sua vez, afirma que a “ideologia de gênero" vem "corromper" e "destruir a inocência" da infância: seu ensino nas escolas daria um "nó na cabeça das crianças", que já não saberiam mais o que são. Vemos, nessa última fala, a associação direta de uma natureza infantil ao gênero da criança, que é afirmado a partir de perspectivas moralizantes, reforçando estereótipos de feminilidade e masculinidade.

Damares Alves (2018)13, em uma extensa palestra sobre "ideologia de gênero" promovida pela comunidade católica Maria de Nazaré, alerta: "a infância está sob risco no Brasil". Afirma, sem apresentar fundamentações, que "juízes, promotores e profissionais da saúde chegaram à conclusão que a ideologia faz mal às crianças".

\footnotetext{
9 Algumas repercussões midiáticas da vinda de Butler: "Petição pedindo o cancelamento da vinda de Butler contou com 373 mil assinaturas", disponível em <https://citizengo.org/pt-br/fm/108060cancelamento-da-palestra-judith-butler-no-sesc-pompeia>

${ }^{10}$ Fala de Kataguiri. Disponível em: <https:/ / www.youtube.com/watch?v=CD8hh85C9AI>

11 "Márcio França aprovou a ideologia de gênero para crianças?". Disponível em: $<$ https://www.youtube.com/watch?v=Ug0cOJyoW_Q>

12 "Judith Butler, a bruxa da ideologia de gênero". Disponível em: <https://www.youtube.com/watch?v=7msVAgSG9ok>

${ }^{13} \mathrm{~A}$ atual ministra é também pastora. Suas palestras estão disponíveis no Youtube e também em sites que se dizem "a favor da criança e da família". Em muitos desses eventos, Damares usa camisetas com frases de efeito remetendo à proteção das crianças. Disponível em: $<$ https:/ / www.youtube.com/watch?v=KoRT5cU57cQ\&t=2619s>
} 
da proteção à instrução: mobilizações prático-discursivas em torno da infância

Para a ministra, a "ideologia de gênero" atua da seguinte maneira: 1. promovendo a "desconstrução da família natural", que se daria, segundo Alves, pela desconstrução da figura do pai e da mãe. Suas afirmações são paradoxais, pois, ao mesmo tempo em que apresenta uma pretensão progressista de se posicionar favoravelmente a outras formas da parentalidade, evoca em suas falas o medo de que as figuras do casal heterossexual sejam "dissolvidas"; 2. pela "desconstrução da heteronormatividade". Na visão da ministra, os "ideólogos de gênero" entendem que ser heterossexual não pode ser sinônimo de normalidade. De fato, os estudos de gênero têm trabalhado com noções como heterossexualidade compulsória e heteronormatividade há pelo menos quatro décadas. Porém, o sentido conferido pela ministra a essa discussão é outro, uma vez que a mesma não faz referência às noções de desigualdade de direitos, ou mesmo de abjeção, vulnerabilidade e violência de gênero, conceitos caros ao campo dos estudos de gênero e de sexualidade. Seu argumento em relação à heteronormatividade desvia a atenção desse complexo debate conceitual, e enfatiza que, com a "ideologia de gênero", haveria uma "imposição social" à experimentação: os jovens estariam se "declarando bissexuais" por pressão social, o que poderia gerar conflitos e confusão ${ }^{14}$.

Por fim, 3. estimularia a "desconstrução e subversão das identidades". Essa desconstrução ocorreria, para Damares Alves, pela suposta crença dos "ideólogos" de que a raça humana seria superior e não deveria ser guiada pela condição biológica, uma vez que a teoria queer ${ }^{15}$ preconizaria a não existência de homens e mulheres. Logo, conclui a ministra, também não existiriam mais gays e lésbicas. A confusão e a colagem das noções de identidade, gênero e orientação sexual é constante em suas palestras ${ }^{16}$. Nessa mesma palestra, Alves (2018) afirma que

as senadoras, a Vanessa, a Gleisi, a Regina17, lutaram pela ideologia de gênero [...] agora olha o tiro no pé, o TSE, vocês sabem que $30 \%$

14 Entrevista de Damares para BBC. Disponível em: <https://www.bbc.com/portuguese/brasil48479429>

15 Vale destacar que a ministra menciona a teoria queer em diversas de suas falas.

16 De maneira geral, o campo dos estudos de gênero e sexualidade, assim como os movimentos sociais, distinguem a identidade de gênero, isto é, como o sujeito se percebe em relação ao próprio sexo/gênero, da orientação sexual, que diz do seu desejo e práticas sexuais. A esse respeito, ver Jesus (2012).

${ }^{17}$ Refere-se às ex-senadoras Vanessa Grazziotin (PCdoB), Gleisi Hoffmann (PT) e Regina Sousa (PT). 
das vagas são para mulheres. Agora o TSE disse que esses 30\% elas vão ter que dividir com todos os gêneros. Elas estão revoltadas [...] Agora vão ter que dividir os $30 \%$ com gays, travesti, lésbicas, transexual, transgênero, intergênero, binário, não binário, espírito livre [...] $\mathrm{O}$ movimento feminista se enganou. $\mathrm{O}$ movimento foi usado pelos ideólogos de gênero.

A consequência demagógica extraída pela ministra a leva a concluir que, a partir da influência da "ideologia de gênero", meninos de seis anos estariam querendo "trocar de sexo" porque é "moda". Os grupos "hoje no Brasil" achariam que "ser transgênero é normal" (Alves, 2018). Apesar das grandes confusões teóricas, sua posição é taxativa: devem ser vedadas as discussões sobre gênero na infância. Afinal, a "ideologia de gênero" seria uma forma de

violência contra a criança. Não é diversidade sexual, não estou falando dos homossexuais, das lésbicas ou das travestis. É além disso. Escolheram o Brasil como laboratório dessa teoria, mas estamos mandando um recado que acabou a brincadeira, nossas crianças não são cobaias. Aos que têm dúvidas do que falo, estudem um pouco sobre o que é a teoria queer. Ela se distancia da comunidade LGBT, tornando-se até mesmo, um antagonista, contra a comunidade LGBT e da comunidade conservadora, ela quer ferir a todos 18

Dentre diversos pontos passíveis de análise, um deles é o pânico moral presente na associação entre infância e gênero. Ele é sustentado, em suas diferentes apresentações e narrativas, pela adesão de grande parcela da população que, de fato, crê que uma maior diversidade social se aproximaria da dissolução de valores familiares e sociais já cristalizados. A partir do medo, surge a crença de que algo deve ser feito e combatido. No caso brasileiro, toda a especulação e criação de fake news em torno do "kit gay" fomentou a crença na "destruição da família tradicional" e, em última instância, da própria educação. Afinal, ao desmantelar essa ideia de infância, o próprio futuro estaria em risco ${ }^{19}$.

A argumentação pelo pânico converge para a figura da criança, através da ideia de progresso e da necessidade de proteção nela contida, mas também a partir da íntima conexão entre infância e os perigos da diversidade sexual e de gênero. Balieiro (2018) busca entender como, no Brasil, a infância é associada ao gênero no campo da política, e recupera a transição governamental de 2010 para 2011 quando,

\footnotetext{
18 Fala publicada em rede social oficial da ministra em 31/08/2019.

19 Para uma cuidadosa discussão sobre o "kit gay" e a "ameaça" da diversidade, ver Maracci (2019).
} 
da proteção à instrução: mobilizações prático-discursivas em torno da infância

ocupando a presidência pelo Partido dos Trabalhadores, Dilma Rousseff suspendeu em 25 de maio de $2011^{20}$ a divulgação da campanha Escola Sem Homofobia, dando a entender que o material poderia ser nocivo às crianças (Balieiro, 2018). Esse foi um evento embrionário no avanço do ultraconservadorismo no país. Apesar de não haver uma causalidade direta entre essas decisões e a eclosão posterior da ofensiva antigênero no Brasil, já no início da década diversos agentes estavam mobilizando fake news em torno dos assuntos relativos à diversidade sob a fachada de uma “ideologia nefasta” que prejudicaria as crianças (Correa; Kalil, 2020; Maracci, 2019).

Outro momento igualmente importante em que a "ideologia de gênero" compareceu com especial intensidade foi na votação do Plano Nacional da Educação (PNE) em 2014, quando o item sobre combate à discriminação nas escolas foi recusado. Nessa ocasião, a fala de Jair Bolsonaro, então deputado federal, ganhou bastante visibilidade na mídia por equiparar "ideologia de gênero" à pedofilia ${ }^{21}$. Como sistematizam Brandão e Lopes (2018), a pauta do gênero e da sexualidade no texto final do PNE foi comprometida em função da forte articulação dos setores políticos conservadores e cristãos. A redação aprovada do PNE afirma a necessidade genérica de combater "todas as formas de discriminação", sem especificar seus conteúdos.

Após quatro anos em debate, o PNE foi sancionado com o trecho
"polêmico" modificado, sinalizando uma vitória das forças políticas
conservadoras. O apelo que realçava a vulnerabilidade das crianças
em face do poder (subversivo) do estado ecoou mais forte. Assim
como no passado, na conjuntura política atual, os conceitos de
gênero e sexualidade são sempre marcados por impedimentos
políticos contrários às transformações sociais (Louro, 1997).
(Brandão; Lopes, 2018, p. 108)

Os retrocessos que vivemos hoje ecoam algumas das razões que levaram Foucault ([1976] 2006) a escrever o primeiro volume da História da Sexualidade afinal, ao contrário do que pregam alguns parlamentares brasileiros, a sexualidade

\footnotetext{
20 "Dilma Rousseff manda suspender kit anti-homofobia, diz ministro". Disponível em: <http://g1.globo.com/educacao/noticia/2011/05/dilma-rousseff-manda-suspender-kit-antihomofobia-diz-ministro.html>

${ }^{21}$ Fala na íntegra de Bolsonaro. Disponível em:

$<$ https://www.camara.leg.br/internet/SitaqWeb/TextoHTML.asp?etapa=5\&nuSessao=096.1.54.O $\&$ nuQuarto $=10 \&$ nuOrador $=1 \&$ nuInsercao $=0 \& \mathrm{dtHorarioQuarto}=09: 18 \& \mathrm{sg}$ FaseSessao $=\mathrm{BC} \& \mathrm{Data}=0$ 5/05/2011\&txApelido=JAIR\%20BOLSONARO,\%20PP-RJ>
} 
possui uma história. Vemos, em discursos como os de Damares Alves, a defesa de que os pais são os "detentores da verdade", cabendo somente a eles a transmissão do que seria sexualidade - analogia parecida com a utilizada por Foucault quando afirma que a sexualidade na virada do século é silenciosamente enclausurada e confinada no quarto do casal. Vemos uma homogeneização da experiência infantil, não considerando o aspecto ativo e diverso da infância (Salgado; Souza, 2018).

Algo que comparece nesses discursos políticos, mesmo que nem sempre de forma explícita, é a pressuposição de uma infância idealizada, universal. Quando as crianças não são tratadas em suas especificidades, subjaz a ideia de que sejam brancas, magras, sem deficiência, cisgêneras, heterossexuais e de classe média/alta (Oliveira, 2018). Tudo o que foge à coesão desse sistema de inteligibilidade é rapidamente colocado na condição de desvio. Para autores como Erica Burman (2009) e Jens Qvortrup (2015), há um viés econômico e individual contido na ideia de desenvolvimento e de proteção, ponto também discutido por Edelman (2004). A noção de "progresso" age como um termo chave que liga o desenvolvimento individual ao social (nacional ou internacional).

Como afirmam Salgado e Souza (2018, p. 247), “a ideia do desenvolvimento humano é partícipe direta do projeto social da modernidade e adere com perfeição à perspectiva de progresso, que tanto se faz útil à vida produtiva de uma nação quanto à trajetória de vida de uma pessoa singular".

Sobre a questão levantada pelos autores, poderíamos incluir algumas contribuições interessantes aportadas por Lee Edelman (2004). Para o autor, o debate em torno do futuro é essencialmente moldado pela figura da criança e atua como balizador do próprio fazer político. Edelman recorre a algumas campanhas publicitárias envolvendo o então presidente Bill Clinton, e analisa suas falas em defesa da infância. Nessa estratégia marqueteira, promovida pela “Coalizão pelas Crianças da América", Clinton aparecia como um pai preocupado e zeloso, "como alguém comprometido com o bem-estar daqueles menos capazes de cuidarem de si mesmos, e especificamente como defensor das crianças em temas como educação e drogas" (Edelman, 2004, p. 1-2, tradução livre). 
A questão política entra em jogo, visto que “a fantasia subjacente à imagem da Criança ${ }^{22}$ invariavelmente molda a lógica dentro da qual o próprio político deve ser pensado" (Edelman, 2004, p. 2, tradução livre). A figura da criança é a imagem condensada que aparece como um standard da transmissão pautada na noção de futuro e também de progresso, afinal, não conseguimos vislumbrar um futuro sem vinculá-lo a uma projeção e a um desdobramento da infância. Isso é político na medida em que molda algumas intervenções de Estado que, muitas vezes em um ímpeto salvacionista, quer "resguardar" esse futuro melhor. Tal ímpeto não caracteriza apenas um espectro político conservador, mas também habita certo discurso progressista. Todos os lados da política estão investidos de um "futurismo reprodutivo", futuro esse que para Edelman é apenas a repetição do mesmo.

Como vimos nos discursos analisados, há uma suposição e uma reiteração da inocência infantil, e a infância universalizada é tomada como etapa da vida que deve ser protegida, uma vez que é concebida como assexuada e pura, e os "ideólogos de gênero" militariam no caminho oposto a esse imaginário ultraconservador. Porém, essa vaga ideia de proteção - tal como é trazida por diversos atores e atrizes de nosso cenário político - não se dá necessariamente sem riscos. Conforme lembra Qvortrup (2015, p. 13), “talvez até o tempo protegido envolva riscos - particularmente quando toma formas controladoras e paternalistas".

\section{a instrução escolar do gênero e da sexualidade}

A captura da infância pela ofensiva antigênero tem produzido narrativas que apresentam os mais jovens como sujeitos passivos, indefesos e submetidos, nos espaços escolares, à doutrinação de educadores que promoveriam a "ideologia de gênero". Essa afirmação, entretanto, não resiste a uma análise mais acurada. Em primeiro lugar porque, como destacado por Vianna e Unbenhaum (2016) em pesquisa que analisa a produção acadêmica sobre políticas públicas de educação, gênero e sexualidade de 1995 a 2015, a abordagem dessas temáticas nas salas de aula

22 Vale destacar que a Criança aqui referida é o ideal a partir do qual opera o futurismo reprodutivo, ideal esse que não se materializa necessariamente na criança de carne e osso (Edelman, 2004). 
está muito aquém do que se poderia esperar. Além disso, o levantamento aponta para um conservadorismo inerente às práticas pedagógicas escolares, cenário muito distante daquele propagado pelos ultraconservadores na ofensiva antigênero. Em segundo lugar, pesquisas que investigam os processos de subjetivação de estudantes em contextos escolares têm mostrado como as e os discentes não se colocam em posição passiva e submetida nos processos de ensino e aprendizagem (cf. Marafon, 2017; Mattos, 2018).

A articulação desses dois pontos já permite levantar, por si, dúvidas sobre como as temáticas de gênero e sexualidade vêm sendo, de fato, trabalhadas nas escolas. Além disso, permite-nos entrever que esses temas tendem a ser abordados em uma lógica pedagogizante, que os toma como conteúdo a ser ministrado e transmitido por um adulto capaz e experiente, autorizado a ensinar sobre aquilo que as e os estudantes desconheceriam, ou não dominariam.

Furlanetto e colaboradores (2018), em revisão sistemática de estudos empíricos, publicados de 2010 a 2016, que analisam atividades e práticas educativas voltadas para a temática da sexualidade no ambiente escolar, identificam dois aspectos que vão nessa direção. O predomínio de uma perspectiva médicoinformativa, "relacionada estritamente à prevenção de doenças sexualmente transmissíveis e gestação", com foco no "fornecimento de informações relacionadas à biologia do sexo, características sexuais secundárias e atitudes necessárias para a manutenção da saúde" (Furlanetto et al., 2018, p. 560) ganha destaque no levantamento ${ }^{23}$.

Além disso, os autores observam uma falta de formações continuadas (ou capacitações) de educadores/as para que possam desenvolver atividades em perspectivas dialógicas e emancipadoras, que pensem os conteúdos a serem trabalhados levando em consideração os contextos das e dos estudantes. A maior parte das atividades mapeadas na revisão sistemática foi conduzida por sujeitos externos às escolas, em caráter pontual (como projetos ou atividades extraclasse) em sua maioria do campo da Enfermagem. Cotejando os resultados da análise com

\footnotetext{
${ }^{23}$ Os autores sinalizam que as experiências identificadas na revisão sistemática foram realizadas com estudantes adolescentes, não tendo sido relatado nenhum trabalho na temática diretamente com turmas de crianças. Esse aspecto dialoga com o que discutimos na primeira sessão.
} 
da proteção à instrução: mobilizações prático-discursivas em torno da infância

a literatura do campo, os autores afirmam que a ausência de capacitações para docentes trabalharem esses temas de maneira transversal aumenta as chances de que sejam omitidos da sala de aula ou, quando trabalhados, acionem "condutas repressivas, punitivas e discriminatórias." (Furlanetto et al., 2018, p. 563).

As concepções de infância e de adolescência que pressupõem o que seria o "certo" nos processos educativos sustentam-se frequentemente nos referenciais desenvolvimentistas e pedagogizantes, e dão subsídios para propostas que tecnicizam as relações de ensino-aprendizagem. Como afirmam Salgado e Souza (2018, p. 251), em nome “da inocência e do desenvolvimento normativos, cada manifestação das crianças que vai na contracorrente da infância ideal precisa ser capturada pelos aparatos institucionais que os conformam a um 'dever ser'.".

Especialmente a compreensão da "criança" (universalizada e abstrata) como ingênua, incapaz, alheia à sexualidade presente nas relações sociais, mídias e tecnologias que a cercam, também se aproxima de perspectivas abertamente conservadoras. Britzman (1996) nomeia de "medo do contágio" a tripla aposta em que "informações técnicas" sobre sexo e reprodução causariam um aumento da atividade sexual entre adolescentes; de que estudantes são tábulas rasas que quanto "mais sabem, mais praticam"; e que ignorância é "proteção". Como afirma a autora, "o velho dualismo binário da ignorância e do conhecimento não pode lidar com o fato de que qualquer conhecimento já contém suas próprias ignorâncias." (Britzman, 1996, p. 91).

O uso do medo do contágio (ou do pânico moral, como vimos anteriormente) para alarmar sobre os riscos para as crianças quando "expostas" à sexualidade tem sido uma estratégia que atravessa os discursos sobre infância e educação na modernidade, chegando ao contexto atual. Esse uso, entretanto, não se dá sem contradições. Como destaca Leite (2019), para os Projetos de Lei propostos pelo Movimento Escola Sem Partido,

as mesmas crianças e adolescentes que seriam incapazes de reagir a um processo de "sexualização precoce", as mesmas "vítimas da ideologia de gênero", são aquelas e aqueles que estão sendo estimulados a serem agentes, protagonistas na denúncia de seus "professores doutrinadores". Se, por um lado, eles são tomados como puro objeto de violação e controle, de outro, poderiam ser sujeitos 
na mudança da ação educativa voltada a eles. (LEITE, 2019, p. 26, grifos da autora)

As contradições destacadas por Leite explicitam processos políticos que vão na contramão da concepção de crianças e adolescentes como sujeitos de direito, e da educação como produtora de emancipação e pensamento crítico. Mas, para além dos retrocessos que têm sido a marca da ofensiva antigênero, essas contradições também apontam para uma dificuldade que nos parece ser constitutiva dos debates que articulam o campo da infância com questões de gênero e sexualidade. A literatura mostra que as maiores resistências a esse trabalho se localizam majoritariamente do lado dos adultos (políticos, educadores e familiares), e não das e dos estudantes. Como sintetizam Furlanetto e colaboradores (2018, p. 563), “parece existir um temor, por parte dos professores, de que o diálogo sobre sexualidade nas séries iniciais fomente uma antecipação dos comportamentos sexuais, além do receio de provocar conflitos com as famílias.". Reencontramos, aqui, o medo do contágio.

Parte dessa resistência das e dos educadores deve-se, sem dúvidas, ao cenário contemporâneo de vigilância permanente, com efeitos judicializantes sobre práticas docentes que abordam tais temas em sala de aula. Essas não são, entretanto, as únicas dificuldades que se apresentam. Conversar sobre sexualidade (e as questões de gênero aí implicadas) nas escolas exige deslocamentos que podem ser difíceis de sustentar por professoras e professores, pois incidem sobre aquilo que é mais arraigado no exercício da função docente: o saber prévio, o conhecimento adquirido e acumulado a ser transmitido na relação de ensino-aprendizagem.

Dar lugar na escola para as dúvidas, conversas, indagações, estranhamentos e piadas sobre sexo das e dos estudantes, dialogando com elas e eles, implica em alguma medida perder o controle da situação, sujeitando-se a risos, reações de surpresa, curiosidade, repulsa, que não têm lugar prescrito no modelo disciplinar e programático da escola. É encontrar-se, enquanto docente, em situações de não saber o que dizer, ser alvo de piadas, de perguntas sobre sua vida pessoal. Essas questões perpassam a prática docente como um todo. Entretanto, percebemos que os temas de gênero e sexualidade parecem produzir uma preocupação a mais, sobre 
da proteção à instrução: mobilizações prático-discursivas em torno da infância

como manter a situação "sob controle", sem que os lugares institucionais (docente estudante) sejam perturbados ou ameaçados.

Avançando nessa reflexão, é interessante perceber certas aproximações entre o que faz questão nos campos da docência e da sexualidade. Controle ("perder o controle" ou "ter o domínio"), exposição (de si, da intimidade), corporeidade (presença, ausência, abjeção), olhar (observar e ser olhado) são dimensões que estão presentes na escola associadas a vigilância e aprendizado, mas que, ao emergirem no campo do sexual, podem ser fonte de prazer e desejo.

Essas oposições alimentam um vasto imaginário sobre o que caberia ao escolar, de um lado, e o que deveria ser restrito ao sexual, de outro. Entretanto, escola e sexualidade não estão apartadas. Das importantes teorizações freudianas sobre a sexualidade infantil às análises foucaultianas sobre a função da instituição escolar na produção da sexualidade moderna, desembocando nas produções que pensam a relação entre gênero, sexualidade e normatividade, vemos se consolidar um campo diverso que pensa as dificuldades que atravessam a abordagem da sexualidade na escola enquanto dificuldade de se pensar a sexualidade presente na escola.

Partindo da centralidade que Freud dá à curiosidade das crianças na sexualidade infantil, Britzman (2010, p. 92) levanta indagações que põem em xeque a normatização da sexualidade na escola: "a sexualidade não é o problema: ela é o lugar [n]o qual os problemas se afixam. Ao mesmo tempo, a sexualidade está também estruturada por um modo de pensamento que recusa a segurança. Nessa concepção, a sexualidade é vista como diferença." - diferença esta que produz fissuras nos sentidos estabilizados que circulam no espaço escolar.

Se a sexualidade produz diferenças e instabilidades de sentido, ela é frequentemente remetida pelos adultos a inteligibilidades normativas. Carvalho e colaboradores (2012) analisam, a partir de pesquisa de campo realizada em instituições de saúde e educação que atendem o público infanto-juvenil, como nesses espaços há uma indiferenciação entre sexualidade e genitalidade para as e os profissionais que ali atuam. Entretanto, a pesquisa identificou, em observações participantes, que as crianças lidavam com a sexualidade em suas brincadeiras de 
maneira muito mais ampla, fluida e lúdica do que o olhar adulto impunha ao tema. As cenas montadas em brincadeiras de boneca e os diálogos construídos pelas crianças indicavam uma apropriação criativa de práticas, códigos e normas sexuais e de gênero, dando notícias de que as crianças percebem distinções entre infância e idade adulta, mas tencionam essas barreiras ao disputar a sexualidade como tema de suas brincadeiras.

Salgado e Souza (2018), por sua vez, discutem como a dimensão lúdica da sexualidade aparece nas brincadeiras infantis no cotidiano escolar, e produzem espaços dialógicos de desconstrução e interpretação do mundo. Nelas, as disputas de sentido e os tensionamentos de hierarquias e normas são atualizadas em uma lógica que se opõe à literalidade, à proibição e ao "retrato" da realidade. Nesse sentido, vale recuperar a pesquisa de Thorne (1993), que se tornou referência nos estudos de gênero. A autora discute os "cruzamentos de fronteira" nas brincadeiras de meninos e meninas no recreio escolar. Esses atravessamentos das fronteiras de gênero produzem humor, são ambivalentes e põem à mostra a produção social das normatividades.

As brincadeiras são espaço de agência infantil, e para que ela ocorra, é fundamental que a criança deseje brincar. Como propõe Silva (2018), o corpo ludens pode ser pensado como um corpo que se contrapõe ao corpo dócil escolar. Vemos aí articulações potentes entre as abordagens emancipadoras de gênero e sexualidade nas escolas e a brincadeira infantil: ao abrirmos a possibilidade para o imprevisível, para a surpresa, para o desejo sem prescrições, é possível circular entre elas, favorecendo práticas dialógicas.

\section{considerações finais}

Neste trabalho, dedicamo-nos a pensar o lugar que a infância (de maneira universalizada, não problematizada) ocupa em dois contextos prático-discursivos distintos, considerando as ressonâncias entre esses campos: as falas de políticos engajados na ofensiva antigênero no Brasil e o trabalho docente com os temas gênero e sexualidade nas escolas, entendendo que em ambos se dá uma disputa sobre os sentidos de infância e suas articulações - possíveis ou interditas - com questões de gênero e sexualidade. 
da proteção à instrução: mobilizações prático-discursivas em torno da infância

Abordamos separadamente esses contextos, reconhecendo as diferenças significativas entre eles. Mas ao nos debruçarmos sobre as construções narrativas da infância e de como essas construções colocam crianças e estudantes em relação às questões de gênero e de sexualidade, vemos que o lugar dos adultos permanece central para a definição de como os temas podem ou não se fazer presentes na escola. Abrem-se aí questões geracionais que, dependendo de como são propostas ou indagadas, permitem conceber diferentes relações entre adultos e crianças.

É nesse ponto que trazemos a importância da brincadeira para pensar a infância em suas diferentes acepções. A descentralização da ideia de condução e controle do processo pedagógico que atravessa as brincadeiras infantis põe em cena a potência emancipadora da agência das crianças, e inspira reflexões importantes para pensarmos o gênero e a sexualidade fora de perspectivas pedagogizantes.

Iniciamos este trabalho fazendo referência aos ataques que Judith Butler sofreu em sua visita ao Brasil, por atores sociais vinculados à ofensiva antigênero. Para encerrarmos nossas reflexões, trazemos uma contribuição da autora que nos permite pensar a articulação entre gênero, sexualidade e educação sem reforçar normatividades - desejando que, com isso, outras alianças possam ser feitas, inclusive entre adultos e crianças:

\begin{abstract}
Ensinar gênero não é doutrinação: não se diz a uma pessoa como viver; esse ensino abre a possibilidade de pessoas jovens encontrarem seus próprios caminhos em um mundo que, recorrentemente, confronta-os com um espectro estreito e cruel de normas sociais. Afirmar a diversidade de gênero não é, portanto, destrutivo: afirma-se a complexidade humana e cria-se um espaço para que pessoas encontrem seus caminhos dentro dessa complexidade. (Butler, 2019b, s/p, tradução nossa).
\end{abstract}

\title{
referências
}

Alves, Damares. A ideologia de gênero faz mal para a criança. 24 abr. 2018 $<$ https://www.youtube.com/watch?v=KoRT5cU57cQ\&t=2619s>. Acesso em 15 jan. 2020.

Alves, Damares. Damares defende que escolas discutam abstinência sexual e critica Popeye [Entrevista concedida à BBC]. BBC, 31 mai. 2019. <https://www.bbc.com/portuguese/brasil-48479429>. Acesso em 19 jan. 2020.

Balieiro, Fernando de Figueiredo. "Não se meta com meus filhos": a construção do pânico moral da criança sob ameaça. Cad. Pagu, Campinas, n. 53, e185306, 2018. Epub 11Jun-2018. <http://dx.doi.org/10.1590/18094449201800530006>. Acesso em 19 jan. 2020 . 
Brandao, Elaine Reis; Lopes, Rebecca Faray Ferreira. "Não é competência do professor ser sexólogo" O debate público sobre gênero e sexualidade no Plano Nacional de Educação. Civitas, Rev. Ciênc. Soc., Porto Alegre, v. 18, n. 1, p. 100-123, Abr. 2018. <http://dx.doi.org/10.15448/1984-7289.2018.1.28265>. Acesso em 19 jan. 2020.

Britzman, Deborah P. "O que é esta coisa chamada amor? Identidade homossexual, educação e currículo". Educação \& Realidade, v. 21, n. 1. Porto Alegre, janeiro-junho de 1996, p. 71-96.

Britzman, Deborah P. Curiosidade, sexualidade e currículo. In G. L. Louro (Org.), O corpo educado: Pedagogias da sexualidade ( $3^{\mathrm{a}}$ ed, pp. 85-111). Belo Horizonte: Autêntica, 2010.

Burman, Erica. Desenvolvimento desejado? Contribuições psicanalíticas para o antidesenvolvimento psicológico. A peste, v. 1, n. 2, p. 269-294. São Paulo, 2009.

Butler, Judith. Anti-Gender Ideology and Mahmood's Critique of the Secular Age. Journal of the American Academy of Religion, v. 87, n. 4, p. 955-967, 2020. DOI: 10.1093/jaarel/lfz083.

Butler, Judith. Gender in Translation: Beyond Monolingualism. philoSOPHIA. v.9, n. 1, p. 125, 2019a. DOI: 10.1353/phi.2019.0011

Butler, Judith. The backlash against "gender ideology" must stop. Newstatesman America. 21 jan. 2019b. Disponível em: <https://www.newstatesman.com/2019/01/judithbutler-backlash-against-gender-ideology-must-stop>. Acesso em 19 jan. 2020.

Butler, Judith. Problemas de gênero: feminismo e subversão da identidade. 10. ed. Rio de Janeiro: Civilização Brasileira, [1990] 2016.

Carvalho, Cíntia de Sousa; Silva, Elisângela Ribeiro da; Souza, Solange Jobim; Salgado, Raquel Gonçalves. Direitos sexuais de crianças e adolescentes: avanços e entraves. Psic. Clin., Rio de Janeiro, v. 24, n.1, p. 69-88, 2012.

Corrêa, Sonia; Kalil, Isabela. Políticas antigénero en América Latina: Brasil - ¿La Catástrofe Perfecta?. Rio de Janeiro: Observatorio de Sexualidad y Política (SPW), ABIA, 2020. Disponível em: <https://sxpolitics.org/GPAL/uploads/EbookBrasil\%2020200204.pdf> Acesso em 02 fev. 2020.

Corrêa, Sonia. A "política do gênero": um comentário genealógico. Cad. Pagu, Campinas, n. 53, e185301, 2018. Epub 11-Jun-2018. <http://dx.doi.org/10.1590/18094449201800530001>. Acesso em 19 jan. 2020.

Edelman, Lee. No Future: Queer Theory And The Death Drive. Durham: Duke University Press, 2004.

Foucault, Michel. História da sexualidade I: a vontade de saber. 17. ed. Rio de Janeiro: Edições Graal, [1976] 2006.

Furlanetto, Milene Fontana et al. Educação sexual em escolas brasileiras: revisão sistemática da literatura. Cad. Pesqui., São Paulo, v. 48, n. 168, p. 550-571, jun. 2018. <http://dx.doi.org/10.1590/198053145084>. Acesso em 19 jan. 2020.

Halssemann, Joice. Judith Butler, a bruxa da ideologia de gênero e a palestra no Brasil. 31 out. 2017. https://www.youtube.com/watch?v=7msVAgSG9ok. Acesso em: 20 jan. 2020.

Jesus, Jaqueline Gomes de. Orientações sobre identidade de gênero: conceitos e termos. Brasília, 2012. Disponível em: <http://www.diversidadesexual.com.br/wpcontent/uploads/2013/04/G\%C3\%8ANERO-CONCEITOS-E-TERMOS.pdf>. Acesso em 10 jun. 2020.

Junqueira, Rogério Diniz. A invenção da "ideologia de gênero": a emergência de um cenário político-discursivo e a elaboração de uma retórica reacionária antigênero. Rev. psicol. polít., São Paulo, v. 18, n. 43, p. 449-502, dez. 2018. Disponível em <http:/ / pepsic.bvsalud.org/ scielo.php?script=sci_arttext\&pid=S1519549X2018000300004\&lng=pt\&nrm=iso $>$. Acesso em 02 fev. 2020. 
da proteção à instrução: mobilizações prático-discursivas em torno da infância

Kataguiri, Kim. A ideologia de gênero é um câncer para as crianças. 22 nov. 2017. https://www.youtube.com/watch?v=CD8hh85C9AI. Acesso em: 20 jan. 2020.

Kataguiri, Kim. Márcio França aprovou a ideologia de gênero para crianças? 06 set. 2018 https://www.youtube.com/watch?v=Ug0cOJyoW_Q. Acesso em: 20 jan. 2020.

Leite, Vanessa Jorge. A captura das crianças e adolescentes: refletindo sobre controvérsias públicas envolvendo gênero e sexualidade nas políticas de educação. Série-Estudos Periódico do Programa de Pós-Graduação em Educação da UCDB, [S.1.], p. 11-30, dez. 2019. ISSN 2318-1982. doi: <http://dx.doi.org/10.20435/serieestudos.v20i52.1354>. Acesso em 19 jan. 2020.

Maracci, João Gabriel. Reflexões sobre verdade e política: mapeando controvérsias do kit gay. (Dissertação de Mestrado). Programa de Pós-Graduação em Psicologia Social, Universidade Federal do Rio Grande do Sul, Porto Alegre, 2019.

Marafon, Giovanna. Recusa à judicialização e ao Projeto de Lei "Escola sem Partido": análise a partir das ocupações estudantis. Sisyphus Journal of Education. v. 5, n. 1, p. 9-30, 2017. DOI: https://doi.org/10.25749/sis.10478

Mattos, Amana Rocha. Discursos ultraconservadores e o truque da "ideologia de gênero": gênero e sexualidades em disputa na educação. Rev. psicol. polit., São Paulo, v. 18, n. 43, p. 573-586, dez. 2018. Disponível em <http://pepsic.bvsalud.org/scielo.php?script=sci_arttext\&pid=S1519549X2018000300009\&lng=pt\&nrm=iso>. Acesso em 25 jan. 2020.

Oliveira, Megg Rayara. O diabo em forma de gente: (r)existências de gays afeminados, viados e bichas pretas na educação (Tese de Doutorado). Programa de Pós-Graduação em Educação, Universidade Federal do Paraná, Curitiba, 2018.

Paternotte, David; Kuhar, Roman. "Ideologia de gênero" em movimento. Rev. psicol. polít., São Paulo, v. 18, n. 43, p. 503-523, dez. 2018. Disponível em <http:// pepsic.bvsalud.org/scielo.php?script=sci_arttext\&pid=S1519549X2018000300005\&lng=pt\&nrm=iso>. Acesso em 02 fev. 2020.

Prado, Marco Aurélio Máximo; Corrêa, Sonia. Retratos transnacionais e nacionais das cruzadas antigênero. Rev. psicol. polít., São Paulo, v. 18, n. 43, p. 444-448, dez. 2018. Disponível

em

<http://pepsic.bvsalud.org/scielo.php?script=sci_arttext\&pid=S1519549X2018000300003\&lng=pt\&nrm=iso>. Acesso em 02 fev. 2020.

Qvortrup, Jeans. A dialética entre a proteção e a participação. Currículo sem Fronteiras, v. 15, n. 1, p. 11-30, 2015.

Salgado, Raquel Gonçalves; Souza, Leonardo Lemos de. Gêneros, sexualidades e

infâncias: Cenas de crianças na contramão da inocência. childhood and philosophy., Rio de Janeiro, v. 14, n. 29, p. 241-258, 2018. DOI 10.12957/childphilo.2018.30540. Disponível em: <https://www.epublicacoes.uerj.br/index.php/childhood/article/view/30540>. Acesso em 19 jan. 2020.

Silva, Conceição Firmina Seixas. "Infância e percursos escolares: a participação como via para a ressignificação do 'ofício de aluno/a'". Trabalho apresentado no I Seminário Infância e Juventudes em Debate, UFAL - Campus Sertão, 2018. Mimeo.

Thorne, Barrie. Gender Play: Girls and Boys in School. New Brunswick, NJ: Rutgers University Press, 2008.

Vianna, Claudia; Ubenhaum, Sandra. "Contribuições da produção acadêmica sobre gênero nas políticas educacionais: elementos para repensar a agenda". In C. P. Vianna; D. Carreira; I. Leão; et al. Gênero e educação: fortalecendo uma agenda para as políticas educacionais. [S.l: s.n.], 2016.

recebido em: 09.02.2020

aprovado em: 08.06.2020 